\title{
UNA PRIMERA APROXIMACIÓN AL NUEVO SISTEMA CASACIONAL
}

\author{
Juan Alfonso Santamaría Pastor \\ Catedrático de Derecho Administrativo \\ Universidad Complutense de Madrid
}

\begin{abstract}
RESUMEN
El trabajo pretende realizar un análisis del texto de la completa reforma del recurso de casación establecida por la disposición final tercera de la Ley Orgánica 7/2015, de modificación de la Ley Orgánica del Poder Judicial, examinando sus caracteres básicos (principalmente, el nuevo instrumento del certiorari), sus trámites principales y, sobre todo, los problemas operativos que planteará su implantación al Tribunal Supremo.
\end{abstract}

Palabras clave: recurso de casación; interés casacional; preparación e interposición del recurso; problemas de la implantación del sistema.

\begin{abstract}
The work is aimed at carrying out an analysis of the text pertaining to the comprehensive reform of the cassation appeal as established by the third final provision of Organic Law 7/2015, for the modification of the Organic Law of the Judicial Power, by examining its most basic and fundamental characteristics (mainly, the new instrument of certiorari), its main procedures and, above all, any operational problems that may be faced by the Supreme Court with regard to its implementation.
\end{abstract}

Key words: cassation appeal; legal requisites for filing/admitting cassation appeals; drafting of and filing the appeal; problems with the implementation of the system. 


\section{SUMARIO}

I. LOS RASGOS FUNDAMENTALES DE LA REFORMA: 1. Unificación de las casaciones. 2. Ampliación de las resoluciones recurribles. 3. El instrumento del interés casacional objetivo.--II. LA TRAMITACIÓN DEL RECURSO DE CASACIÓN: 1. Preparación del recurso: A) Su falta de justificación. B) Contenido del escrito. C) Los plazos. 2. El trámite de admisión: A) El órgano de admisión. B) La audiencia en caso de dudas sobre la admisión. C) La publicidad de las admisiones. 3. Interposición y oposición: A) La prohibición de entrega de las actuaciones. B) La corrección de malas prácticas de letrado. C) Otras cuestiones. 4. La sentencia.-III. EL FUTURO DE LA REFORMA: LOS PROBLEMAS OPERATIVOS.

Tras una acelerada tramitación parlamentaria (el proyecto de ley entró en el Congreso de los Diputados el 27 de febrero de 2015), el Boletín Oficial del Estado del 22 de julio insertó la Ley Orgánica 7/2015, de modificación de la Ley Orgánica del Poder Judicial, cuya disposición final tercera contiene una nueva y completa regulación del recurso de casación en el proceso contencioso-administrativo ${ }^{1}$. Las profundas innovaciones que esta Ley Orgánica introduce aconsejan emprender un primer acercamiento a su contenido - que, por razones obvias, ha de ser forzosamente sucinto-, con objeto de llamar la atención sobre algunas de las dificultades que habrá de afrontar el nuevo sistema casacional.

Estas dificultades van a producirse no solo en el orden interpretativo, sino, sobre todo, en el operativo. Aunque los nuevos textos reguladores de la casación no están exentos de incertidumbres para su correcto entendimiento, como de inmediato se verá, los principales interrogantes que la reforma plantea son de orden práctico: si las novedades que se introducen van a resultar de utilidad para los fines que persiguen, y si las estructuras formales del Tribunal Supremo se encuentran en situación de aplicar eficazmente el nuevo sistema. Felizmente, los poderes públicos disponen de un plazo razonable para implementar la reforma, que no entrará en vigor hasta el 22 de julio de 2016, de acuerdo con la disposición final décima de la Ley Orgánica.

Aunque la exposición de motivos de la Ley Orgánica no se haga eco de ello, la reforma se propone, implícitamente, hacer frente a algunos

1 Reducida ahora a los artículos 86 a 93 de la Ley; los numerales 94 a 101 desaparecen (literalmente, se «suprimen», en la incorrecta terminología difundida desde hace años para aludir a la derogación).

La referida disposición final tercera aporta también nuevas redacciones a los artículos 102 (recurso de revisión), 108.3 (ejecución de sentencias de condena) y 139 (costas) de la LJCA. Dado el específico objeto del presente estudio, no se tratarán aquí, pese a su relevancia práctica. 
de los problemas capitales que aquejan al actual recurso de casación. Haremos referencia a ellos al hilo de la exposición de las innovaciones introducidas por la Ley Orgánica, que abordamos sin más preámbulos.

\section{LOS RASGOS FUNDAMENTALES DE LA REFORMA}

\section{Unificación de las casaciones}

En muy diversas ocasiones, la doctrina ha puesto de manifiesto la exagerada diversificación que había experimentado el recurso de casación, hasta alcanzar las cinco modalidades actuales: común, para la unificación de doctrina y en interés de la ley, con sus variantes estatal y autonómica en los dos últimos casos.

No parece necesario recordar el estruendoso fracaso que han supuesto los recursos de casación para la unificación de doctrina y en interés de la ley, cuyos mínimos porcentajes de estimación permiten suponer un muy escaso grado de aprecio hacia ellos por parte de los miembros de la Sala Tercera. Personalmente, comparto esta actitud respecto del recurso de casación para la unificación de doctrina, una mala importación del proceso laboral cuyo requisito primordial de admisión (que las sentencias de contraste se hubieran dictado «respecto a los mismos litigantes u otros diferentes en idéntica situación y, en mérito a hechos, fundamentos y pretensiones sustancialmente iguales») llevaba inexorablemente a un alto nivel de inadmisiones, por poco rigor que se empleara en su apreciación. No puedo decir lo mismo, en cambio, respecto de la aparente renuencia a la admisión y estimación de los recursos de casación en interés de la ley, que siempre ha sido, para el que suscribe, el instrumento óptimo de que el Tribunal Supremo disponía para fijar doctrina general; aunque ha de reconocerse que buena parte de los recursos interpuestos por los entes públicos y Corporaciones se han referido a cuestiones quizá muy sensibles para la marcha diaria de los recurrentes, pero de escaso interés desde el punto de vista de la formación de jurisprudencia sobre temas transversales.

La reforma ha optado por la solución de reconducir a un único modelo todas estas modalidades casacionales, con la única salvedad de la instauración de un recurso de casación "común» por infracción de derecho autonómico (art. 86.3, párrafo tercero), cuya ausencia en el momento actual no dejaba de constituir una asimetría sin fundamento. Justo es decir que la simplificación parece claramente afortunada, aunque 
solo sea porque evitará a los litigantes el sufrimiento producido por las irresolubles dudas acerca de la procedencia de interponer recurso de casación común o para la unificación de doctrina (por ejemplo, en los casos de duda acerca de la cuantía del litigio), o los melancólicos esfuerzos empleados en justificar la lesión a los intereses generales en los recursos en interés de la ley, entre otros beneficios.

\section{Ampliación de las resoluciones recurribles}

Como es bien sabido, el artículo 86 - aún vigente- de la Ley Jurisdiccional limita el ámbito del recurso de casación en un doble sentido: excluyéndolo respecto de las sentencias que versen sobre cuestiones de personal al servicio de las Administraciones Públicas o cuya cuantía no exceda de 600.000 euros, y limitándolo a las sentencias y autos dictados por los órganos colegiados de la Jurisdicción (Salas de los Tribunales Superiores de Justicia y de la Audiencia Nacional) que, además, fueren dictados en única instancia (con exclusión, en consecuencia, tanto de las resoluciones dictadas por los Juzgados unipersonales cuanto las de los colegiados en vía de apelación).

Las dos primeras exclusiones que acabamos de mencionar desaparecen de la nueva regulación del recurso, siendo sustituidas por el sistema de apreciación de interés casacional objetivo del asunto litigioso al que poco después nos referiremos. Y, en la misma línea, la Ley amplía el ámbito de resoluciones recurribles por razón del órgano emisor de las mismas, bien que de manera limitada.

1) En cuanto a las sentencias, la nueva Ley, además de confirmar la recurribilidad de las dictadas en única instancia por las Salas de los Tribunales Superiores de Justicia y de la Audiencia Nacional, abre el recurso (i) a las pronunciadas por estos mismos órganos en vía de apelación, y también (ii) a las dictadas en única instancia por los órganos judiciales unipersonales ${ }^{2}$, pero solo cuando estas últimas «contengan doctrina que se reputa ( $\mathrm{sic}$ ) gravemente dañosa para los intereses generales y sean susceptibles de extensión de efectos» (art. 86.1, párrafo segundo).

2 Con su sostenida tendencia a olvidar los Juzgados Centrales, la nueva redacción del artículo 86 continúa hablando de "los Juzgados de lo Contencioso-administrativo», expresión que, en puridad, es solo aplicable a los órganos que menciona el artículo 6.a) de la Ley, pero que, sin duda, se emplea en sentido comprensivo de aquéllos (lo mismo ocurrió en la versión original del artículo 78, que solo fue corregida con la Ley 37/2011). 
a) La comprensión de este doble requisito de recurribilidad de las sentencias dictadas en única instancia por los órganos judiciales unipersonales plantea algunas dificultades.

El primero de estos requisitos (que las sentencias «contengan doctrina que se reputa gravemente dañosa para los intereses generales») es, precisamente, una de las circunstancias determinantes del posible interés casacional [la mencionada en el nuevo artículo 88.2.b)]; lo que, dicho sencillamente, parece significar que el recurso no podrá ser admitido por concurrir en él cualquier otro de los supuestos del mencionado interés casacional, sino solo por el antes referido (o por éste y por algún otro, conjuntamente, claro está).

Y, en cuanto al segundo (que las sentencias «sean susceptibles de extensión de efectos»), su redacción guarda cierta semejanza con otra de las circunstancias determinantes del posible interés casacional [la mencionada en el artículo 88.2.c): que la sentencia «afecte a un gran número de situaciones, bien en sí misma o por trascender del caso objeto del proceso»]; pero, a mi juicio, alude a otro supuesto distinto, el regulado en el artículo 110: en concreto, a las sentencias dictadas «en materia tributaria, de personal al servicio de la Administración pública y de unidad de mercado», que hubieran reconocido «una situación jurídica individualizada a favor de una o varias personas».

El juego conjunto de ambos requisitos hace augurar un futuro nada halagüeño — al menos, a corto plazo - a los recursos de casación que se interpongan contra las sentencias de los órganos judiciales unipersonales: no me refiero tanto a la radical reducción de los motivos de interés casacional invocables cuanto a los criterios sumamente restrictivos que la Sala Tercera ha venido manteniendo, desde hace años, respecto de la apreciación del grave daño a los intereses generales en el marco del recurso de casación en interés de la ley (art. 100.1). No es desdeñable la posibilidad de que estos criterios se extiendan al nuevo recurso de casación contra sentencias de los Juzgados (aunque tampoco cabe descartar un cambio de estos criterios, lo que sería realmente deseable); más aún, teniendo en cuenta la dificultad de identificar un interés «general» en sentencias que, como las de los Juzgados, versan mayoritariamente sobre cuestiones de ámbito municipal.

b) Con referencia también a las sentencias, es conveniente señalar algunas otras innovaciones. No las hay en lo que afecta a la exclusión del recurso de casación de las dictadas en el procedimiento para la protección del derecho fundamental de reunión y en los procesos contencioso-electorales, que hoy se contiene en las letras c) y d) del vigente ar- 
tículo 86.2 , y que el nuevo artículo 86.2 reproduce. Pero sí se suprime la recurribilidad en todo caso de las sentencias que «declaren nula o conforme a Derecho una disposición de carácter general» (art. 86.3 hoy vigente); tal recurribilidad se condiciona ahora a que se aprecie en el objeto del litigio un interés casacional derivado de la relevancia que la disposición impugnada posea [nuevo art. 88.2.g)].

2) El régimen de recurribilidad de los autos merece también algún comentario.

a) Respecto de los autos dictados por los órganos judiciales colegiados, la reforma se limita a dos modificaciones poco perceptibles (el «nuevo» artículo 87 reproduce casi literalmente el texto del mismo número de la Ley aún vigente, hasta el punto de reproducir la expresión «recurso de súplica», que la Ley 13/2009, de 3 de noviembre, sustituyó por la de «recurso de reposición»).

De una parte, el párrafo inicial del nuevo artículo 87.1 sustituye la referencia a «los mismos supuestos previstos en el artículo anterior» por la fórmula «con la misma excepción e igual límite dispuestos en los apartados 2 y 3 del artículo anterior». El cambio de redacción es afortunado, pues la del aún vigente artículo 87.1 es bastante inexpresiva: queda ahora mucho más claro que no serán recurribles los autos dictados en los procesos para la protección del derecho fundamental de reunión y contencioso-electorales (art. 86.2), y que será exigible, en los recursos contra los autos, el juicio de relevancia que continúa exigiendo el nuevo artículo 86.3. Pero la fortuna se detiene en el nivel de la redacción, porque lo que no tiene sentido alguno es el mantenimiento del citado juicio de relevancia en los recursos contra autos: los motivos de ilegalidad que pueden esgrimirse contra los enumerados en las cinco letras de este artículo 87.1 son —en la inmensa mayoría de los casos, si no en todos- infracciones de la propia Ley de lo Contencioso, norma perteneciente indiscutiblemente al ordenamiento estatal, de manera que el juicio de relevancia se convierte, en estos casos, en una alegación sumaria y sin contenido material alguno: un requisito puramente formalista, por inútil.

Hay también, en el propio artículo 87.1, una modificación que podría pasar fácilmente desapercibida. En la redacción aún vigente del artículo, el apartado 2 dispone que los autos dictados en aplicación de los artículos 110 y 111 serán susceptibles de recurso de casación «en todo caso»; lo cual supone que no les es exigible el cumplimiento de los requisitos del anterior artículo 86. En el texto resultante de la reforma, sin 
embargo, la referencia a dichos autos deja de situarse en un apartado independiente [pasando a integrarse en el apartado 1 como letra e)], y desapareciendo también la alusión a la recurribilidad «en todo caso»; lo cual parece suponer que, en lo sucesivo, será exigible a los recursos contra los autos de extensión de efectos de la sentencia el requisito, ya mencionado, del juicio de relevancia; un juicio igualmente superfluo, puesto que los recursos correspondientes habrán de basarse siempre en la vulneración de los citados artículos 110 y 111 de la propia Ley Jurisdiccional.

b) En una primera y rápida lectura de la Ley de reforma pudiera concluirse, a contrario sensu, que la nueva regulación excluye por completo el recurso de casación contra los autos dictados por los órganos unipersonales de la Jurisdicción, ya que el artículo 87.1 solo alude a los provenientes de las Salas de lo Contencioso-Administrativo de la Audiencia Nacional y de los Tribunales Superiores de Justicia. Pero esta conclusión dista mucho de ser incuestionable en lo que se refiere a las resoluciones de dichas Salas en recursos de apelación contra los autos dictados en primera instancia por los Juzgados de lo Contencioso; cuestión ésta que la nueva regulación deja irresuelta.

Veamos: de hecho, los recursos de apelación contra autos de los Juzgados unipersonales se resuelven, en la inmensa mayoría de los casos, mediante sentencia, como ordena el apartado 9 del artículo 85 de la Ley vigente; en otros supuestos, en cambio, se resuelven mediante auto (p. ej., los que confirman la inadmisión de un recurso). Si la apelación se resuelve mediante sentencia, parece —en principio- que el recurso de casación contra ésta debería regirse por la regla del artículo 86.1 (recurso contra sentencias en apelación); pero la redacción del párrafo segundo del citado artículo 86.1 parece indicar que dicho precepto solo se refiere a las sentencias dictadas en apelación contra sentencias de los Juzgados unipersonales (no contra autos); y, desde luego, no sería aquí aplicable el artículo 87.1, que solo alude a los recursos contra autos dictados por los órganos colegiados de la Jurisdicción.

Esta aparente laguna podría resolverse, de forma expeditiva, en el sentido de negar la recurribilidad en casación de estas sentencias: dado el carácter extraordinario de este recurso, podría entenderse que la relación de resoluciones recurribles constituye un numerus clausus, quedando excluidas de aquél cualesquiera resoluciones no explícitamente aludidas en los artículos 86 y 87 . Pero, aparte de que estas soluciones interpretativas son siempre insatisfactorias, por simplistas, cabe advertir que no tiene mucho sentido presuponer que la Ley de reforma 
haya permitido los recursos de casación contra sentencias dictadas en apelaciones contra sentencias, y excluido el recurso contra las sentencias que resuelvan recursos de apelación contra autos, siendo así que muchos autos tienen tanta o más importancia que las sentencias y que no pocos prejuzgan el fondo del asunto (me refiero a los dictados en las piezas de medidas cautelares que entran de lleno en el plano de la apariencia de buen derecho).

¿Quid de los recursos de apelación (contra autos) resueltos también mediante auto? Pues resulta que el párrafo inicial del artículo 87.1 no contiene la precisión del artículo 86.1, silenciando si quiere referirse solamente a los autos dictados en única instancia, o también a los emitidos en apelación. Y este silencio puede ser interpretado en dos sentidos opuestos: primero, en un sentido positivo, entendiendo aplicable por analogía la regla del artículo 86.1 (si es recurrible en casación la sentencia dictada en apelación contra una sentencia, parece que también habrá de serlo el auto que resuelve la apelación contra otro auto). Y segundo, naturalmente, negando la posibilidad del recurso: si el artículo 86.1 solo admite con hartas restricciones la casación contra sentencias dictadas en apelación, la ausencia de toda mención a los autos dictados por los Juzgados unipersonales parece dar a entender la voluntad del legislador de no abrir la vía casacional respecto de estos autos.

Es evidente que el autor de estas líneas podría optar por cualquiera de las soluciones antes expuestas, y defenderla dialécticamente. Es más honesto, sin embargo, reconocer que ello sería producto de una opción puramente arbitraria - porque todas ellas son igualmente defendibles- y esperar a que sea el propio Tribunal Supremo quien resuelva la cuestión. Y no es malicioso suponer que, al menos en los primeros momentos, se optará por la solución de la irrecurribilidad de unas y otras resoluciones judiciales, como dique de contención frente a la previsible avalancha de recursos que se producirá con la apertura de la casación a las sentencias dictadas en apelación (contra sentencias).

\section{El instrumento del interés casacional objetivo}

1) La previsión de tal avalancha no es temeraria. En el pasado año 2014, las Salas de los Tribunales Superiores de Justicia y de la Audiencia Nacional dictaron un total de 58.692 resoluciones definitivas, que dieron lugar a 5.566 recursos ante el Tribunal Supremo. Pero las resoluciones emitidas por Juzgados unipersonales (142.443) más que du- 
plicaron la primera de las cifras anteriores; por lo que, aun contando con que un alto porcentaje de estas resoluciones no sea objeto de recurso de casación, no parece exagerado suponer que el número de asuntos que ingresen anualmente en el Tribunal Supremo se multiplicará por dos o más ${ }^{3}$. Todo ello nos lleva al tema central de la reforma.

2) En todas las jurisdicciones administrativas europeas, la congestión de asuntos que sufre la máxima instancia jurisdiccional ha constituido, desde hace largo tiempo, una de las preocupaciones principales de los poderes públicos (y, naturalmente, de los litigantes). Y España no ha permanecido inmune a este mal: lo acreditan las cifras de las estadísticas oficiales, que es conveniente recordar en sus aspectos esenciales.

Asuntos en el Tribunal Supremo (Sala 3. $\left.{ }^{a}\right)^{4}$

\begin{tabular}{lcrcc}
\hline & Ingresados & Resueltos & En trámite & T/M resolución \\
\hline 2003 & 10.057 & 9.530 & 21.381 & 23,9 \\
2004 & 11.395 & 10.321 & 24.522 & 26,6 \\
2005 & 12.384 & 13.179 & 21.391 & 27,0 \\
2006 & 12.374 & 12.850 & 17.279 & 26,7 \\
2007 & 8.997 & 11.451 & 14.719 & 22,5 \\
2008 & 7.900 & 9.191 & 13.426 & 20,9 \\
2009 & 9.489 & 9.655 & 13.260 & 18,8 \\
2010 & 8.993 & 9.079 & 17.070 & 17,2 \\
2011 & 8.342 & 10.089 & 12.322 & 18,8 \\
2012 & 5.835 & 9.910 & 8.084 & 16,5 \\
2013 & 5.150 & 6.705 & 6.546 & 15,5 \\
2014 & 5.565 & 5.566 & 6.545 & 14,7 \\
\hline
\end{tabular}

3 Las cifras anteriores están tomadas de los resúmenes de la estadística judicial (Justicia Dato a Dato), obrantes en la web del Consejo General del Poder Judicial (http://www.poderjudicial.es/cgpj/es/Temas/Estadistica-Judicial/Analisis-estadistico/La-Justicia-dato-a-dato). Estos datos, no obstante, han de relativizarse levemente, ya que el número de resoluciones definitivas dictadas por los órganos colegiados que se cita comprende también las recaídas en apelación; y el volumen de asuntos ingresados en el Tribunal Supremo comprende, también, los recursos directos contra los actos y disposiciones mencionados en el artículo 12.1 de la Ley. A efectos de los grandes números que se manejan, estas precisiones son, a nuestro juicio, escasamente relevantes.

4 Las cifras están tomadas de la misma fuente citada en la nota anterior, que solo alcanza, en el pasado, al primero de los años que se reseñan; las de ejercicios anteriores serían muy similares, pienso, en cuanto a la tendencia.

Advirtamos que entre los datos de cada año existen, en dicha fuente, diferencias de número no explicadas en cuanto a los tiempos medios de resolución (expresados en meses); he tomado en todo caso las cifras más elevadas. Dichas cifras son muy escasamente realistas, como conoce perfectamente cualquier profesional de los que nos hemos dedicado durante años 
No es objeto de este trabajo emprender un análisis de dichas cifras, que habrá de dejarse para otra ocasión. A los efectos que aquí interesan, bastará señalar dos cosas: primera, la evidencia de que el número de recursos contenciosos ingresados en el Tribunal Supremo (al igual que en el conjunto de órganos que integran la Jurisdicción) guarda un estrecho paralelismo con la marcha general de la economía española ${ }^{5}$; s segunda, que las soluciones legislativas improvisadas para frenar el crecimiento de asuntos (exclusión en bloque de la casación de determinadas materias o de litigios referidos a la infracción de normas autonómicas, desplazamiento de la competencia para determinados asuntos a órganos judiciales de nivel inferior, etc.) se han revelado de muy escasa utilidad, salvo la muy traumática de la drástica elevación del umbral casacional que realizó la Ley 37/2011, de 10 de octubre ${ }^{6}$.

Las consecuencias de este fenómeno de congestión son, también, harto conocidas, aunque raramente expuestas con total franqueza: se ha prestado una especial atención a la extraordinaria demora en la emisión de los fallos (algo, sin duda, sumamente nocivo para la finalización de los conflictos y la seguridad jurídica), dejando en la penumbra otro efecto perverso de la congestión, la premura que impone en el estudio y deliberación de los asuntos. Me referiré a ello en la parte final de este trabajo.

Las cifras del cuadro antes expuesto no deben inducir, por lo demás, a conclusiones optimistas, que serían engañosas. Es cierto -innegable- que la reducción del stock de asuntos pendientes y la disminución

a litigar ante la Sala Tercera, a los que nos consta que el tiempo real para la resolución por sentencia de los recursos multiplicaba por dos y por tres los tiempos mensuales que figuran en el cuadro. Probablemente no se trate de un error técnico, sino que derive de la falta de desglose entre los asuntos que llegaban a sentencia y los que morían en el trámite del artículo 93, cuyo tiempo procesal de vida era mucho más breve.

5 Las cifras de la primera columna muestran un crecimiento estimable y sostenido de asuntos durante los últimos años del boom económico (2003-2006), con un hundimiento sensible de más del 30\% en 2007, primer año de la crisis (de 12.374 en 2006 a solo 8.997 en 2007); disminución que continuó paulatinamente durante los años siguientes (salvo en 2009) hasta tocar fondo (igual que la economía) el ejercicio de 2013, con solo 5.150 nuevos recursos. El pequeño repunte experimentado en 2014 (+415 recursos) parece también tener algo que ver con el comienzo de la recuperación económica.

Por supuesto, las causas de esta evolución no se encuentran solo en las vicisitudes del ciclo económico: el aumento del número de recursos es también, a mi juicio, una consecuencia del incremento de la regulación y el crecimiento de los efectivos burocráticos de todas las Administraciones.

${ }^{6}$ Cuyo efecto tampoco puede magnificarse. Es evidente que el número de recursos ingresados en el año 2011 (8.342) disminuyó fuertemente el ejercicio siguiente (5.835); pero parte al menos de esta disminución debe imputarse al hecho de que el 2012 fue el año en que la crisis económica se mostró con mayor violencia. En contraste, y contra lo que se supone generalmente, el establecimiento de las tasas judiciales (Ley 10/2012, de 20 de noviembre) no parece haber constituido un desincentivo demasiado potente para el planteamiento de recursos de casación, ya que el descenso (no excesivo) de su número en 2013 debe también ser atribuido, en parte, a la agudización de la crisis. 
de los tiempos reales de resolución se deben, en buena parte, al esfuerzo considerable desarrollado por el colectivo de Magistrados de la Sala Tercera, que sería injusto desconocer; pero no lo es menos que estos brillantes resultados se han conseguido, también, mediante la puesta en práctica de otros instrumentos mucho menos dignos de elogio, como han sido las divisiones artificiales de la cuantía de los recursos con objeto de reducirla por debajo del umbral casacional, la conversión fáctica del escrito de preparación en un avance del de interposición, o el reproche de ausencia o insuficiencia del juicio de relevancia exigido por el artículo 86.4 de la Ley vigente.

No hay afán de crítica alguna al dejar constancia de estos artificios: es comprensible que, ante la pasividad del legislador, la Sala Tercera tuviera que improvisar estos procedimientos para finalizar de modo expeditivo, y con un consumo mínimo de tiempo de trabajo, una buena cantidad de asuntos, en aras de no prolongar de forma escandalosa el plazo de emisión de los restantes fallos. La situación que se vivió en 2004, con cerca de veinticinco mil asuntos pendientes y plazos de resolución muy superiores a la cifra que figura en el cuadro anterior ${ }^{7}$, era realmente explosiva y explica, si no justifica, todas estas medidas de urgencia.

Por ello, ha de considerarse como una muestra de lucidez de los legisladores no haberse dejado engañar por la línea descendente en el número de recursos y en los tiempos medios de resolución. Es muy probable que la mejora de la situación económica y el mayor talante intervencionista de los nuevos gobiernos autonómicos y locales lleven, en poco tiempo, a un incremento sensible del número de asuntos de los que haya de conocer la Sala Tercera; lo cual, unido a la decisión política de abrir el recurso a las sentencias dictadas en apelación y a las provenientes de los Juzgados unipersonales, ha forzado a implantar abiertamente el sistema de certiorari, generalizando la institución ya apuntada (y escasamente aplicada) en el artículo 93.2.e) de la Ley reguladora de la Jurisdicción.

3) Lo que este término significa es casi innecesario explicarlo, por notorio. Se trata de la atribución a la Sala Tercera de un poder de selección de los asuntos a resolver empleando el exclusivo criterio

\footnotetext{
7 Me refiero a los plazos reales, que en aquel entonces oscilaban, en la mayor parte de los casos, entre cuatro y seis años, como acredita la simple comparación entre la fecha de las sentencias entonces dictadas y el año de interposición de los recursos respectivos. Por supuesto, se dictaban sentencias en plazos menores (véase, por ejemplo, y entre otras muchas tomadas al azar, la STS de 27 de octubre de 2004, con número de recurso 82/2003), pero también otras en términos muy superiores (en la misma fecha, por ejemplo, la STS de 27 de octubre de 2004, con número de recurso 4571/1995).
} 
del «interés casacional objetivo para la formación de jurisprudencia» (art. 88.1) que ofrezcan las cuestiones debatidas en el recurso. Este requisito opera conjuntamente con el de la presunta concurrencia de «una concreta infracción del ordenamiento jurídico, tanto procesal como sustantiva, o de la jurisprudencia».

a) Ante todo, es digna de destacar la desaparición de la relación de específicos motivos de ilegalidad invocables que figuran aún en el artículo 88.1 de la Ley. Aunque tal desaparición sea obligada, por inútil, en un sistema de certiorari, ha de celebrarse vivamente, no solo por razones de coherencia lógica [como he señalado en otro lugar, los motivos de las letras a), b) y c) del artículo 88.1 no eran más que innecesarias especificaciones del motivo de la letra d): infracciones del ordenamiento jurídico o de la jurisprudencia], sino también para eludir la gratuita angustia creada a los litigantes, forzados a acertar en la invocación del motivo exactamente aplicable en los numerosos supuestos fronterizos que en la práctica existen.

La exigencia de este requisito de admisión, junto al del interés casacional del asunto, plantea, no obstante, algunas dudas a las que más adelante me referiré.

b) La expresión «interés casacional objetivo» sorprende, en primer lugar, por la incorporación de su segundo adjetivo. Ignoro su origen e intención, que probablemente pretende ser una llamada de atención a los litigantes: el interés casacional es un rasgo del asunto vinculado a la apreciación por la Sala de la estricta conveniencia de un fallo que cree jurisprudencia; algo, por tanto, completamente ajeno al interés o repercusión que una decisión judicial pueda tener en el patrimonio jurídico de los recurrentes. Hecha esta aclaración (que bien podría haber sido hecha en la exposición de motivos de la Ley Orgánica), el adjetivo es perfectamente prescindible; y así lo haremos en este trabajo.

c) La configuración del interés casacional se ha realizado mediante una doble relación, indicativa y no exhaustiva («entre otras circunstancias»: art. 88.2), de supuestos en los que tal interés puede apreciarse, que es notablemente más amplia que la existente en otros tipos de procesos: recordemos que, en el orden civil, el interés casacional solo puede apreciarse «cuando la sentencia recurrida se oponga a doctrina jurisprudencial del Tribunal Supremo o resuelva puntos y cuestiones sobre los que exista jurisprudencia contradictoria de las Audiencias Provinciales o aplique normas que no lleven más de cinco 
años en vigor» (art. 477.3 LEC). Con la excepción del último supuesto, tal circunstancia se prevé en los apartados 2.a) y 3.b) del artículo 88; pero el número de circunstancias que permiten la apertura de la vía casacional contenciosa es muy superior, como acreditan las minuciosas relaciones de los apartados que acaban de citarse.

La distinción entre las circunstancias que permiten a la Sala Tercera «apreciar que existe interés casacional objetivo» (ap. 2) y aquellas otras en las que "se presumirá que existe interés casacional objetivo» (ap. 3) no es fácilmente inteligible, salvo por mera aproximación y con un importante grado de sutileza. En realidad, y a pesar del equívoco que puede suscitar la redacción del párrafo inicial del apartado 3 ( «Se presumirá que existe interés casacional objetivo»), uno y otro listado enumeran situaciones de hecho puramente indiciarias de la existencia de un interés casacional, que puede concurrir, o no, en cada concreto recurso, y cuya apreciación es enteramente libre por parte de la Sala. El hecho de que, respecto del listado del apartado 2, la existencia de interés casacional haya de motivarse expresamente en el auto de admisión, como ordena el artículo 90.3.a), solo indica que su apreciación en los supuestos del apartado 3 es más libre, no precisando que sea motivada. La presunción de que habla el párrafo inicial de este apartado no es, en ningún caso, juris et de jure, ya que todos sus subapartados [salvo la letra b)] permiten expresamente una valoración de la Sala en la que se declare la inexistencia de interés casacional ${ }^{8}$. Dicho lisa, llanamente y sin ningún error: es previsible que sea más fácil que se aprecie la concurrencia de este interés en los supuestos del apartado 3 que en los del 2 , aunque solo sea porque la negativa a aplicarlo exige una motivación específica de la Sala, que no es cómodo elaborar en ningún caso. Pero el nivel de posibilidad de que un asunto sea considerado de interés casacional dependerá mucho más de las características del concreto problema interpretativo que se plantee, que de la concurrencia de una circunstancia de un listado, o del otro.

d) No tendría especial utilidad comentar cada una de las circunstancias que figuran en los dos listados a que nos estamos refiriendo. En términos generales, todos ellos son bastante razonables; y su interpretación y alcance solo podrán apreciarse una vez transcurran algunos meses, o años, desde su aplicación efectiva, una vez que se disponga de un número significativo de decisiones de la Sala.

8 Y ello incluso en el supuesto de la letra b), que acabamos de mencionar, ya que la jurisprudencia existente de la que se aparte la sentencia recurrida puede referirse a cuestiones nimias o de nulo interés general. 
A priori, no obstante, pueden formularse algunos reproches a su redacción. Sin pretender ser exhaustivos, se echa en falta en ellos algunas situaciones que, a mi entender, hubieran merecido ser calificadas como de interés casacional, como las de inaplicación de una ley por infracción del Derecho comunitario [ap. 2.d)]; y, en sentido contrario, me parece dudoso que puedan tener interés casacional, por regla general, los recursos sobre convenios interadministrativos [ap. 2.h)] o los interpuestos contra acuerdos de los organismos reguladores [ap. 3.d)]. La referencia que esta última letra hace a las agencias estatales parece, por lo demás, fuera de lugar, ya que la competencia para conocer de recursos contra sus actos no corresponde a la Sala de la Audiencia Nacional, sino a los Juzgados Centrales [art. 9.1.c): la Agencia de Protección de Datos que menciona el apartado 5 de la disposición adicional cuarta no es, técnicamente hablando, una Agencia estatal].

\section{LA TRAMITACIÓN DEL RECURSO DE CASACIÓN}

El nuevo texto de los artículos 89 a 93 no introduce modificación alguna en la estructura general del procedimiento de recurso hoy vigente, el cual continúa asentado sobre los trámites de preparación, admisión, interposición, oposición y sentencia. Las innovaciones de detalle son, en cambio, muy numerosas, y deben examinarse con cierto detenimiento.

\section{Preparación del recurso}

\section{A) Su falta de justificación}

De entrada, el mantenimiento que la reforma hace del trámite de preparación del recurso, así como su contenido, han de calificarse sencillamente de incomprensibles. La experiencia ha revelado, hasta el hartazgo, que la preparación no ha servido en absoluto - salvo supuestos excepcionales de recursos manifiestamente improcedentescomo un filtro a utilizar por los órganos judiciales autores de las resoluciones recurridas, los cuales tienen por preparados los recursos sin apenas atender a los respectivos escritos. Antes bien, este trámite se ha utilizado tácticamente, como antes aludimos, como un instrumento de inadmisión a limine de múltiples recursos por la Sala Tercera, en los supuestos de discordancia entre los escritos de preparación y de in- 
terposición, por ausencia en el primero de los concretos motivos de casación que pretendían utilizarse, de la justificación del carácter estatal o comunitario de las normas presuntamente infringidas, o por falta o insuficiencia del llamado juicio de relevancia. De su nula utilidad procesal dice bastante el hecho de la no exigencia de este requisito en los aún vigentes recursos de casación para la unificación de doctrina y en interés de la ley (arts. 97.1 y 100.3).

Todos estos requisitos artificiales, impuestos al margen de la Ley por una doctrina jurisprudencial bien conocida, son objeto ahora de una legalización expresa en el artículo 89.2, y con un inusual grado de detalle. Y ello supone un esfuerzo doblemente inútil: primero, porque priva prácticamente de sentido al posterior escrito de interposición del recurso, que en la actualidad se limita a reproducir lo ya especificado en el de preparación, con algunos leves desarrollos, normalmente superfluos por repetitivos. Y segundo, porque es perfectamente innecesario obligar a los recurrentes a confeccionar un escrito lleno de una larga y minuciosa serie de requisitos formales (la mayor parte de ellos, obvios), con objeto de propiciar su inadmisión en los casos de ausencia o error, cuando la admisión a trámite del recurso viene a ser, en virtud del certiorari, una decisión prácticamente libre de la Sala, se cumplan o no los requisitos formales de viabilidad del recurso.

Dicho con todo respeto al legislador, es insostenible que un requisito formal, perfectamente prescindible en la redacción literal del vigente artículo 89.1 y 2, y ampliado por la jurisprudencia como una técnica de facilitación de las inadmisiones, no solo se haya mantenido en la Ley de reforma, sino que sus exigencias se hayan agravado. No sé si peco de optimismo al pensar que, en el momento en el que el régimen de certiorari funcione ya con normalidad, el legislador optará por suprimirlo; que es lo que debía haber hecho en esta ocasión.

\section{B) Contenido del escrito}

Cuanto acaba de decirse viene confirmado por la lectura del apartado 2 del artículo 89, ninguno de cuyos cinco primeros epígrafes soporta la valoración más complaciente posible. Solo el contenido en la letra f) (la argumentación acerca del interés casacional del asunto) posee una justificación evidente; el resto podrían y deberían ser suprimidos sin perjuicio alguno para la mecánica de la admisión del recurso, al referirse a requisitos formales que la Sala debería fiscalizar de 
oficio y sin previas aclaraciones de la parte recurrente; aclaraciones que, en caso de duda, podrían hacerse en el posterior trámite de alegaciones que regula el artículo 90.1 (equivalente al previsto en el artículo 93.3 del texto de la Ley aún vigente).

a) La letra a) del artículo 89.2 coincide con el vigente artículo 89.1, sin más que especificar los «requisitos de forma exigidos» a los que este último alude. Como sabemos todos quienes redactamos habitualmente este tipo de escritos, se trata de una mera reiteración de obviedades, relativas a requisitos apreciables, de oficio y sin el menor esfuerzo, por la Sala sentenciadora; produce vergüenza ajena tener que repetir, por ejemplo, que el conocimiento del recurso de casación corresponde a la Sala Tercera del Tribunal Supremo (que ahora no parece que habrá que repetir). Este denodado empeño en la mención de los requisitos formales del recurso contrasta vivamente con el hecho de que uno de ellos sea el de la legitimación para recurrir, siendo así que la Ley Orgánica ha olvidado reproducir el vigente artículo 89.3, que precisa quiénes ostentan tal requisito; el cual seguirá siendo un requisito porque lo dice el artículo 89.2.a), pero no «reglado», ya que no se regula en lugar alguno.

b) Tiene una cierta coherencia que la letra b) exija al recurrente «identificar con precisión las normas o la jurisprudencia que se consideran infringidas». Pero la utilidad de este requisito resulta discutible si se tiene en cuenta que la especificación de dichas normas y decisiones jurisprudenciales no vincula en absoluto a la Sala Tercera, la cual —art. 90.4- podrá pronunciarse sobre la interpretación de cualesquiera otras, si así lo aconsejara el desarrollo del debate. En el aspecto positivo, es de elogiar que este precepto haya completado lo actualmente dispuesto en el artículo 86.4, permitiendo la invocación no solo de las normas o jurisprudencia alegadas por las partes o consideradas por la sentencia recurrida, sino también de las que ésta hubiera debido considerar y aplicar, aun no habiendo sido invocadas.

La letra b) parece limitar la obligación del recurrente a «identificar» las normas o jurisprudencia infringidas, esto es, a efectuar su cita o referencia exacta (por ejemplo, «el art. 44.1, párrafo segundo, de la Ley Reguladora de la Jurisdicción Contencioso-Administrativa»), excluyendo las invocaciones imprecisas (esto es, «las normas sobre transparencia de la legislación de contratos públicos»). El empleo de este verbo puede llevar, sin embargo, al desconcierto, ya que la posterior exigencia de justificar la relevancia de la infracción sobre la decisión 
adoptada en la resolución que se pretende recurrir [art. 89.2.d)] implica la necesidad de un cierto desarrollo del contenido de la norma y de su infracción por la sentencia (de otra manera, su relevancia o carácter determinante difícilmente podrán ser demostrados). Sin perjuicio de que habrá de esperar a conocer las rutinas que en este punto vaya estableciendo la Sala Tercera, la prudencia parece aconsejar una mención de las normas o jurisprudencia algo más expresiva y detallada que su mera «identificación».

c) La letra c) del artículo 89.2 constituye una reiteración del actual artículo 88.2, que impide a los recurrentes invocar la infracción de las normas relativas a los actos y garantías procesales si no se hubiera «pedido la subsanación de la falta o transgresión en la instancia». La norma no ofrece dificultades de interpretación, pero su fundamento es absolutamente endeble y disfuncional, por lo que su mantenimiento en la Ley de reforma no resulta de recibo. Su fundamento es muy débil, porque en la instancia no es posible apreciar, en muchos casos, si una posible irregularidad cometida por el tribunal $a$ quo va a causar indefensión o si, por el contrario, va a ser irrelevante: por ejemplo, en la denegación de un medio de prueba aparentemente de escaso interés que, sin embargo, la sentencia toma posteriormente como punto básico de su argumentación. Y es, por ello mismo, una exigencia disfuncional, que inclina a las partes a protestar y recurrir toda decisión interlocutoria del órgano de instancia con carácter puramente preventivo, trufando el proceso de recursos e incidentes continuos y dilatando su tramitación. Es patente que esta disposición no es más que un viejo artificio destinado a eliminar artificialmente motivos casacionales, que carecerá de sentido y utilidad en el régimen de certiorari, en el que el Tribunal Supremo podrá elegir casi discrecionalmente los extremos sobre los que habrá de pronunciarse.

d) Igualmente cuestionable es el mantenimiento del tan citado juicio de relevancia, hoy contenido en el artículo 86.4 y ahora plasmado en la letra d) del artículo 89.2. Lo es porque su cumplimiento es superfluo o problemático: es completamente superfluo en un recurso de contenido simple: si lo que se discute (y nada más) es si una liquidación tributaria contraviene el artículo 25 de la Ley del Impuesto sobre el Valor Añadido, el juicio de relevancia es perfectamente ocioso. Pero si el debate sobre la legalidad de un acto administrativo ha exigido el examen y la invocación concurrente de diferentes preceptos legales o de doctrinas jurisprudenciales, cada uno de los cuales tiene un dife- 
rente peso específico en la estructura de la argumentación, afirmar o negar la relevancia o carácter determinante de cada una de ellas es, si no imposible, algo enteramente opinable, convencional y arbitrario. En muchos casos, no se trata de un hecho objetivo, sino de una cuestión de perspectiva; y los requisitos de admisibilidad de los recursos no pueden diseñarse como la consecuencia de un juicio de valor infiscalizable.

Hay más, no obstante. De la misma manera que sucede con el requisito de la letra c), el carácter determinante del fallo de las normas o jurisprudencia infringidas es una circunstancia absolutamente ajena a la finalidad propia del sistema de certiorari. En él, el recurso de casación no es más que un motivo, poco más que un pretexto, para que el Tribunal Supremo seleccione un punto concreto del debate en la instancia sobre el que crea oportuno sentar doctrina jurisprudencial; da igual que la norma invocada haya sido determinante o se trate de un mero obiter dictum, porque ese obiter puede convertirse, si no es corregido por la sentencia de casación, en el precedente y argumento determinante en procesos posteriores.

e) El requisito de la letra e) del artículo 89.2 puede tener una cierta justificación, habida cuenta de la prohibición implícita que se impone al Tribunal Supremo de fallar sobre la interpretación de normas de las comunidades autónomas. Solo tiene sentido y utilidad, sin embargo, cuando las invocadas por las partes en la instancia (o las tenidas en consideración por la sentencia) tengan, simultáneamente, dicho origen, junto con otras pertenecientes al ordenamiento estatal o comunitario. Pero la división de competencias que se practica en estos supuestos, y que ha dado lugar a una abundante jurisprudencia, tiene efectos seriamente insatisfactorios, ya se deriven de la abstención de pronunciarse sobre las normas estatales (o autonómicas) invocadas, cuando se considere que unas u otras no constituyen el fundamento del fallo, o se divide la continencia de la causa, pronunciándose el Tribunal Supremo sobre la interpretación de las normas estatales y remitiendo al Tribunal Superior de Justicia la decisión sobre las autonómicas. Es éste un arduo problema que bien hubiera merecido una reflexión y solución por los autores del texto de la Ley de reforma. 


\section{C) Los plazos}

Las decisiones del legislador son frecuentemente erráticas y contradictorias. Esta calificación bien puede aplicarse a los dos plazos establecidos en los apartados 1 y 5 del artículo 89.

Respecto del primero (plazo de presentación del escrito de preparación) solo cabe resaltar su acierto. El actual plazo de diez días para formalizar el escrito de preparación se amplía ahora hasta treinta, una extensión harto razonable si se tienen en cuenta los abrumadores requisitos formales que el artículo 89.2 impone a este escrito; los diez actuales resultaban manifiestamente cortos para redactar un escrito prácticamente idéntico al de interposición, máxime cuando el letrado al que se encomendara su elaboración fuera otro diferente al que llevó el asunto en la instancia.

Por el contrario, no se entiende que el apartado 5 mantenga un plazo de igual duración para llevar a cabo la personación ante el Tribunal Supremo cuando el órgano judicial a quo haya tenido por preparado el recurso. En el régimen actual, tal plazo puede estar justificado por el hecho de que el recurrente ha de elaborar en el mismo el escrito de interposición; pero tras la reforma, el trámite de personación del recurrente no ha de ir acompañado del escrito de interposición, cuya presentación solo procederá una vez que el recurso de casación haya sido admitido por la Sala Tercera (art. 92.1). Con toda evidencia, dar más de un mes para redactar y presentar un escrito de menos de un folio de extensión y sin contenido técnico alguno es un exceso gratuito, que dilata innecesariamente la tramitación del recurso.

\section{El trámite de admisión}

Modificando la estructura del iter procedimental del recurso, el nuevo artículo 90 prevé la celebración de un trámite de admisión del recurso preparado, que tiene lugar antes de la formalización del escrito de interposición; en el régimen aún vigente, dicho trámite se realiza teniendo a la vista el citado escrito de interposición (art. 93), que ha de presentarse en el plazo de treinta días que se concede a las partes para la comparecencia ante el Tribunal Supremo.

El contenido del nuevo artículo 90 ofrece muchas cuestiones que merecerían un comentario en un análisis más en profundidad de la Ley. En esta primera aproximación habremos de limitarnos a glosar las más señaladas. 


\section{A) El órgano de admisión}

Aunque el apartado 1 del artículo 93 de la Ley aún en vigor prevé que la admisión o inadmisión del recurso se acuerde por la Sala a propuesta del Magistrado ponente (el que habrá de elaborar el proyecto de sentencia), es notorio que tal decisión es adoptada por la Sección Primera de la Sala (compuesta por el Presidente de la misma y por los Presidentes de cada una de las restantes Secciones). Por más que el fundamento legal de este modus operandi sea dudoso, ha de reconocerse que se trata del mejor de los sistemas posibles, en cuanto asegura (al menos, en un nivel aceptable) la uniformidad en la aplicación de los criterios de admisión o inadmisión.

Sin perjuicio de algunos desfallecimientos, es notorio que este sistema de organización del trabajo ha funcionado de forma bastante satisfactoria. Y ello hace muy difícilmente comprensible la ocurrencia de la Ley de reforma según la cual la Sección que ha de resolver sobre la admisión o inadmisión de los recursos estará compuesta por el Presidente de la Sala (menos mal) y "por al menos un Magistrado de cada una de sus restantes Secciones» (no necesariamente por sus Presidentes); colectivo este que, además, «se renovará por mitad transcurrido un año desde la fecha de su primera constitución y en lo sucesivo cada seis meses, mediante acuerdo de la Sala de Gobierno del Tribunal Supremo» (art. 90.2).

Es realmente muy difícil cometer mayor número de desaciertos en un solo precepto legal, modificando las raras cosas que funcionan bien para sustituirlas por otras que es absolutamente seguro que funcionarán mal. Quien ha de velar por la identidad de criterios aplicados por un órgano colegiado es precisamente su presidente, no cualquiera de sus miembros, por inteligentes y capaces que sean; máxime, cuando los criterios a unificar se refieren a cuestiones tan impalpables y opinables como es la existencia de interés casacional en un determinado debate procesal. Y el desatino alcanza su mayor nivel con la implantación de un sistema rotatorio (¡cada seis meses!), que lo único que garantiza es que lo que puede ser de interés casacional en mayo no lo sea en julio. Si el recurso de casación tiene por finalidad fundamental sentar criterios unitarios y estables sobre la interpretación de las normas jurídicas, mucho más importante es asegurar que la apreciación del citado interés casacional responda a pautas igualmente unificadas y perdurables en el tiempo. Como abogado en ejercicio, entre otros innumerables, creo tener derecho a que los criterios determinantes del interés casacional sean no solo conocidos, sino previsibles por su estabilidad, a 
menos de condenarnos a no poder aconsejar a los litigantes que acuden en busca de nuestros servicios sobre la viabilidad del recurso que proyectan interponer.

Como dice el pueblo llano, hay veces en que el legislador no lo hace peor porque no entrena lo suficiente.

\section{B) La audiencia en caso de dudas sobre la admisión}

El artículo 93.3 del texto aún vigente de la Ley prevé, para los casos en que la Sección Primera albergue dudas sobre la admisibilidad de un recurso de casación, que "pondrá de manifiesto sucintamente la posible causa de inadmisión del recurso a las partes personadas por plazo de diez días para que formulen las alegaciones que estimen procedentes». El apartado 1 del nuevo artículo 90 prevé un trámite semejante, pero de caracteres muy distintos.

a) Para empezar, se trata de un trámite puramente potestativo y singular: la Sección de admisiones —llamémosla así- "podrá acordar, excepcionalmente y sólo si las características del asunto lo aconsejan, oír a las partes personadas por plazo común de treinta días acerca de si el recurso presenta interés casacional objetivo para la formación de jurisprudencia»; lo cual conlleva, en román paladino, que la inadmisión pueda acordarse sin oír a ninguna de las partes, al contrario de lo que hoy prescribe la Ley.

Hay, sin duda, razones que pueden explicar esta drástica solución, ya utilizada hace tiempo por el Tribunal Constitucional (art. 50 LOTC); la más consistente de ellas, la posible escasa utilidad de un debate procesal sobre una cuestión estrictamente opinable y no objetivable. Pero ya es bastante que el Tribunal Supremo pueda negarse a conocer del recurso de un ciudadano simplemente por no considerar de interés las cuestiones que plantea, para que, adicionalmente, esto se haga sin darle la oportunidad de exponer, al menos, razones adicionales a las ya manifestadas en el escrito de preparación.

b) La inadmisión del recurso de casación puede acordarse no solo por no apreciarse en él suficiente interés casacional, sino también por ausencia o infracción de los restantes requisitos formales, como puntualmente precisa el apartado 4 de este mismo artículo. ¿Procede en estos casos el trámite de audiencia previsto en su apartado 1? Y si procediera, ¿también habrá de concederse solo «excepcionalmente y sólo si las características del asunto lo aconsejan»? 
Parece evidente que este silencio solo puede atribuirse al olvido del redactor de la norma. En el texto aún vigente de la Ley, la audiencia del recurrente en los supuestos de duda acerca de la observancia de los requisitos formales es preceptiva en todo caso, como acabamos de recordar; y si pudiera tener alguna justificación prescindir de este trámite en relación con la ausencia de interés casacional, por su apreciación prácticamente discrecional, no la tiene, desde luego, cuando lo que se discuta es una cuestión básicamente reglada, como puede ser el cumplimiento del plazo de preparación o el carácter recurrible de la sentencia. En tales supuestos, la audiencia de las partes parece venir exigida por un elemental principio de contradicción procesal.

\section{C) La publicidad de las admisiones}

El apartado 7 del nuevo artículo 90 ordena la publicación de los autos de admisión de los recursos en la página web del Tribunal Supremo, así como la inserción, en la misma página web y en el Boletín Oficial del Estado, con carácter semestral, del «listado de recursos de casación admitidos a trámite, con mención sucinta de la norma o normas que serán objeto de interpretación y de la programación para su resolución».

Ciertamente, cualquier medida de difusión del trabajo de la Sala Tercera ha de ser bienvenida, y más en un ámbito tan inicialmente difuso como es la apreciación del interés casacional. Pero esta publicación va a tener únicamente utilidad para los órganos jurisdiccionales que tengan pendiente el fallo de asuntos en los que precisamente se debata la aplicación de las normas cuya interpretación solemne anuncie el Tribunal Supremo; para las partes y sus asesores, ninguna. Mucho más útil, para unos y otros, sería la publicación de las providencias y autos de inadmisión y de las cuestiones sobre las que versaran, que probablemente evitaría la formulación de muchos recursos condenados de antemano al fracaso; admitimos que tal publicación tendría unas dimensiones desmesuradas y que exigiría la inversión de un importante número de horas de trabajo para los servicios del Alto Tribunal, dado el elevado número de recursos que habrán de interponerse en los próximos años; pero éste debiera ser un objetivo que la Sala se marque para un horizonte no muy remoto, aunque la Ley no lo exija.

Y lo mismo ha de decirse del inexplicable silencio que la Ley de reforma guarda sobre la ulterior publicación de las sentencias que resuelvan los recursos de casación admitidos: de bien poco sirve que el Tribunal Supremo anuncie en internet que se propone dar una interpre- 
tación jurisprudencial formal a una norma si luego no se informa de cuál ha sido tal interpretación. Lo lógico sería que, tras dictarse la sentencia, se insertara su fecha y datos de localización (p. ej., el número de autos, o la clave del CENDOJ) en el mismo listado y página web a que se refiere este artículo 90.7, sin remitir tácitamente a jueces y letrados a intentar localizarla periódicamente en el pozo sin fondo que sigue siendo la base de datos del Centro de Documentación Judicial.

\section{Interposición y oposición}

La celebración del debate entre las partes se regula en la Ley de reforma en términos muy similares a los que hoy continúan vigentes, centrándose en dos escritos de fondo - de interposición y de oposición al recurso-, uno y otro a formular sucesivamente en plazo de treinta días, además de la posibilidad adicional de celebrar vista pública. Las modificaciones que se introducen son contadas, de escasa importancia e inspiradas por preocupaciones puramente domésticas o de reacción a comportamientos de las partes que judicialmente se consideran inadecuados. Mencionemos algunas de ellas.

\section{A) La prohibición de entrega de las actuaciones}

A este orden de las preocupaciones domésticas pertenecen las reglas de los apartados 1 y 5 del artículo 92, tendentes a proscribir la costumbre de algunos letrados de solicitar la entrega de los autos y del expediente administrativo para formalizar los escritos de fondo antes mencionados; entrega que se excluye tajantemente advirtiendo que «las actuaciones procesales y el expediente administrativo estarán de manifiesto en la Oficina judicial». La repercusión práctica de esta medida, en orden al efectivo derecho de defensa, es más importante de lo que parece, ya que la información que pueden ir acumulando motu proprio los letrados durante la instancia es siempre incompleta; y es frecuente que el letrado a quien se confíe la llevanza del recurso de casación sea otro distinto del que actuó en la instancia (el cual, en no pocos casos, habrá sido separado del asunto por el recurrente, lo cual no juega precisamente a favor de colaborar con el nuevo). Pero, además, es imposible redactar solventemente un escrito de cierta complejidad y delicadeza sin tener a la vista continuamente los autos y el expediente administrativo en el mismo centro de trabajo en el que el escrito se 
redacta, no en una oficina judicial que hoy por hoy no dispone de salas adecuadas a este fin; remitir la solución de cada duda a una visita a las instalaciones del palacio de la plaza de la Villa de París es un perfecto disparate, y más para un letrado residente en A Coruña, Puigcerdá o Tarifa.

\section{B) La corrección de malas prácticas de letrado}

Permítaseme la libertad de calificar afectuosamente como manías algunas otras reglas de nuevo cuño, con las que pretenden corregirse algunos comportamientos discutibles de los letrados que actúan ante el Tribunal Supremo. A este género pertenecen la habilitación a la Sala de Gobierno del Tribunal Supremo para imponer «la extensión máxima y otras condiciones extrínsecas, incluidas las relativas a su presentación por medios telemáticos, de los escritos de interposición y de oposición» (art. 87 bis, 3) ; el recordatorio de que el escrito de interposición ha de razonar por qué han sido infringidas las normas o la jurisprudencia mencionadas en el escrito de preparación, «sin poder extenderse a otra u otras no consideradas entonces» [art. 92.3.a)]; y la aclaración de que las sentencias que sean invocadas como jurisprudencia infringida deben ser «analizadas y no meramente citadas» (ibídem) ${ }^{10}$.

De estas tres minuciosas prescripciones, la primera solo puede calificarse de pintoresca. Comparto plenamente la censura, muy frecuente en el mundo judicial, de que los escritos procesales de las partes suelen ser desmesurada e innecesariamente extensos ${ }^{11}$; y los letrados

\footnotetext{
9 No aludiremos a los dos restantes apartados del artículo mencionado, que son puramente reiterativos de reglas establecidas en los artículos 93.3 y 93.1, respectivamente. Sin embargo, no puedo dejar de hacer constar la extrañeza de que se haya insertado un artículo bis, siendo así que la reforma suprime por completo seis artículos, dejando vacíos los correspondientes numerales. El desprecio del legislador por las cuestiones formales (su incuria, en términos de T. R. FERNÁNDEZ) alcanza aquí cotas pavorosas.

10 No son las únicas, por lo demás. Suscita sonrisas la previsión hecha en el párrafo inicial del artículo 92.3 en el sentido de que el escrito de interposición deberá exponer las infracciones denunciadas y las pretensiones que se esgrimen «en apartados separados que se encabezarán con un epígrafe expresivo de aquello de lo que tratan»; esta bienintencionada regla (cuya razón y finalidad no pueden ser en absoluto censuradas) constituye un reproche implícito al sistema educativo, del que han desaparecido prácticamente los viejos ejercicios de redacción de tiempos pasados; pero también una lamentación por las crecientes dificultades expositivas de las nuevas generaciones, que abominan de los libros. Este objetivo difícilmente podrá conseguirse sin imponer una inviable prohibición formal a los letrados de intervenir sistemáticamente en los chats de Facebook o Twitter.

11 Lo cual es imputable a causas múltiples, y no solo a la creciente ausencia de capacidades expresivas y de síntesis: el empleo de procesadores de textos tiene mucho que ver en esta práctica, pero también el deseo de satisfacer a su cliente, magnificando con la extensión el interés que reviste para él el recurso.
} 
que trabajan conmigo pueden dar fe de mi continuo empeño en lograr la máxima concisión en su redacción. Pero fijar de antemano una dimensión máxima de los escritos es un perfecto disparate, producto del más rancio arbitrismo, que desconoce la radical diferencia de complejidad que existe entre unos y otros recursos; como lo demuestra el que, en algunos casos, las dimensiones de la sentencia exceden de las muy notables de los escritos de las partes. Sería mucho más operativo que las propias sentencias de casación contuvieran amonestaciones formales a los letrados por los excesos físicos de sus escritos (y también, en ocasiones, por su oscuridad y desorden).

La segunda regla acoge la doctrina jurisprudencial, ya mencionada, que exige una perfecta correlación entre los motivos anunciados en el escrito de preparación y los desarrollados en el de interposición; una regla que no tiene más sentido y utilidad que facilitar la inadmisión de recursos, objetivo ahora innecesario en el régimen de certiorari; y una regla, además, que se halla en manifiesta contradicción con la establecida en el nuevo artículo 90.4, según el cual la sentencia podrá extenderse a la interpretación de normas distintas de las anunciadas por el recurrente "si asi lo exigiere el debate finalmente trabado en el recurso». Si el debate es el factor que habilita a la Sala a extenderse a la interpretación de otros preceptos, parece evidente que las partes han de estar autorizadas para invocarlos. ¿En qué quedamos?

La tercera y última previsión antes citada trae causa de las quejas, habitualmente manifestadas en privado por los miembros de todos los órganos judiciales, de la viciosa práctica seguida por innumerables letrados de limitarse a mencionar, a favor de sus tesis argumentales, una o varias sentencias, transcribiendo a continuación su texto, pero sin apuntar su conexión temática con el objeto del proceso. La norma es sin duda razonable, por más que su aplicación no pueda ser excesivamente estricta y general, salvo obligando a los letrados a exponer razonamientos apodícticos en aquellos casos en los que la jurisprudencia no exige comentario alguno: por ejemplo, la doctrina que prohíbe a las partes demandantes formular pretensiones reconvencionales, o la que impide a un órgano jurisdiccional basar su fallo en un motivo no esgrimido por las partes sin previamente ponérselo de manifiesto. Las prácticas de los malos letrados no se corrigen con disposiciones como ésta. 


\section{C) Otras cuestiones}

La anteposición temporal del trámite de admisión del recurso a la formalización del escrito de interposición del mismo ha obligado al legislador a prever una segunda ocasión de inadmitir el recurso en los supuestos en los que el escrito citado no reúna los requisitos que enumera el artículo 92.3. La previsión en este punto del artículo 92.4 es lógica, pero reserva algunas sorpresas. La primera, que para estos casos se establezca la obligación de oír a la parte recurrente; lo que parece obligado, pero que contrasta (favorablemente, desde luego) con el silencio que guarda la Ley respecto de la inadmisión del recurso por defectos formales del escrito de preparación, que ya antes mencionamos. La segunda, que se exija para la inadmisión la forma de sentencia en lugar de la de auto, tratándose de un defecto menor. La tercera, de mucha menor importancia, que no se prevea el plazo que ha de concederse para la audiencia. Y cuarta y última, que se prevea la imposición al recurrente de las costas por este incidente; algo metafísicamente imposible, ya que en el mismo no tiene intervención alguna la otra parte.

\section{La sentencia}

La regulación de la sentencia de casación (arts. 92.8 y 93) ofrece muy escasas novedades respecto de la regulación vigente. Su simple mención bastará para tomar noticia de ellas.

1) En primer lugar, la regulación que el artículo 93.1 hace de los contenidos de la sentencia es parcialmente correcta: separa con claridad los pronunciamientos interpretativos de las normas invocadas por las partes (que son preceptivos en todo caso), y el fallo de revocación o confirmación de la sentencia o auto impugnados. Olvida, en cambio, la decisión sobre las pretensiones de reconocimiento de situaciones jurídicas individualizadas (defecto en el que también incide el artículo 87 bis, 2, por cierto), pero que ha de tenerse por implícitamente aceptado. Y, sobre todo, resulta chocante, ante las vacilaciones que ha dado lugar en la práctica, que no se prevea la posibilidad de una sentencia de inadmisión (o de desestimación por defectos formales): parece deducirse de ello (aunque esta conclusión ha de expresarse con muchas reservas) que el legislador ha querido excluir la facultad de la Sección 
competente para resolver el recurso de contradecir el criterio de la Sección de admisiones; esta exclusión parece lógica y defendible en lo que se refiere a la apreciación del interés casacional, pero no lo es tanto en lo que afecta a la estimación de defectos formales (recurribilidad de la sentencia o auto, plazo de preparación y/o de interposición, etc.). Lo que haya de suceder solo nos lo dirá la práctica; pero hubiera sido conveniente que el legislador hubiese dedicado algunas líneas a resolver estos problemas de discrepancia interna en el seno de la Sala Tercera.

2) En segundo lugar, también se echa de menos una solución más contundente a la difícil opción, tan frecuentemente planteada a la Sala, entre la retroacción de las actuaciones y devolución de las mismas al órgano de instancia para que el proceso siga el curso ordenado por la ley hasta su culminación, y la decisión directa sobre estos vicios formales por la propia Sala del Tribunal Supremo. El artículo 93.1 parece limitarse a enunciar un criterio restrictivo de los supuestos de retroacción, que solo procederán «cuando justifique su necesidad»; lo cual es tendencialmente correcto, pero quizá hubiera sido preferible establecer una regla según la cual la retroacción de actuaciones solo procedería en los casos en que la Sala Tercera no se encontrara en condiciones de dictar una resolución de fondo sobre las pretensiones materiales de la parte recurrente sin celebrar nuevas actuaciones probatorias.

3) La Ley de reforma introduce una innovación sustancial en el régimen de las costas (me refiero exclusivamente a las causadas en el recurso de casación, no a las de la instancia, cuya normación también se modifica en la nueva redacción del artículo 139). En la versión aún vigente, el artículo 139.3 prevé la imposición de las costas al recurrente con arreglo al principio del vencimiento total (esto es, «si se desestima totalmente el recurso»); esta redacción había llevado a la jurisprudencia a excluir tal condena tanto en los casos de estimación parcial del recurso como en los de inadmisión, lo que es una muestra de la renuencia con la que un sector de la Sala Tercera había acogido la reforma que impuso el principio de vencimiento.

Modificando este criterio, el artículo 93.4 vuelve al criterio original de la Ley Jurisdiccional, ordenando que cada parte abone «las causadas a su instancia y las comunes por mitad», sin perjuicio de imponerlas a una sola de ellas «cuando la sentencia aprecie, y así lo motive, que ha actuado con mala fe o temeridad». La solución ha de ser enjuiciada como lógica, puesto que el servicio a la claridad del ordenamiento 
que presta el recurrente al plantear una cuestión que reviste interés casacional compensa sobradamente el que sus pretensiones carezcan de fundamento bastante.

4) Por último, y a título de mera curiosidad (la cuestión es irrelevante), no quisiera dejar de mencionar la picardía de que hace gala el artículo 92.8 al fijar el plazo en el que ha de dictarse la sentencia: mantiene el plazo de diez días que continúa figurando -incomprensiblemente- en el artículo 67.1 de la Ley, pero fijando el dies a quo para su cómputo no en la fecha en la que se hayan declarado conclusas las actuaciones, sino «desde que termine la deliberación para votación y fallo». Sin perjuicio de que esta regla sea bastante más realista, el precepto incurre en una clara incorrección técnica, puesto que la sentencia «se dicta» en el momento de terminar la deliberación sobre la ponencia; cosa distinta es su redacción, plasmación en papel, firma y notificación a las partes, actuaciones que serán las que deban realizarse en el plazo que este precepto establece.

\section{El FUTURO DE LA REFORMA: LOS PROBLEMAS OPERATIVOS}

Decíamos al comienzo de esta colaboración que los problemas que habrá de afrontar la puesta en práctica de esta profunda reforma no son tanto de carácter interpretativo cuanto operativo; problemas que, a mi juicio, son muy serios y preocupantes y que no pueden omitirse en este primer análisis.

A) Hay, en primer lugar, dos arduos retos a los que la Sala Tercera (pero también el Consejo General del Poder Judicial y el propio Gobierno) habrá de hacer frente en la segunda parte del ejercicio de 2016, cuando la reforma entre en vigor.

De una parte, un incremento sustancial del número de recursos que se interpongan, que se producirá con toda probabilidad como consecuencia de su apertura a las sentencias dictadas en apelación o por los Juzgados unipersonales, y de la supresión de la eliminación de las exclusiones de los asuntos de personal y del umbral cuantitativo de la casación. No sería sorprendente que el número de recursos ingresados en 2016 sea un 50\% superior a los interpuestos en el presente año, y que esta cifra se duplique en 2017. El esfuerzo de tramitación que ello ha de suponer habrá de ser extraordinario, y más si se suman, a los nuevos recursos, los que ingresen de enero a julio de 2016 y los que en 
este mes queden aún pendientes del «antiguo régimen» (que, recordemos, eran 5.566 a primeros de 2015).

Y, de otra parte, un incremento igualmente considerable del tiempo de estudio que requerirá cada uno de los recursos: en la actualidad, y si mis informaciones no son inexactas, cada recurso es objeto de un estudio superficial, referido a cuestiones puramente formales, en el trámite de admisión regulado en el artículo 93 (que es realizado en una primera fase por los Letrados del Gabinete) y, posteriormente, de un examen en profundidad por parte del Magistrado de la Sección al que corresponda preparar la ponencia. La implantación del sistema de certiorari obligará a transformar el primer análisis de admisión en un examen a fondo del recurso, tan intenso y exigente como la preparación posterior de la ponencia, y en el que habrá que formar criterio sobre la concurrencia o no de interés casacional en el asunto.

B) Ambos retos obligan a interrogarse sobre si los efectivos personales de la Sala Tercera son suficientes y adecuados para hacerles frente, con objeto de que la entrada en funcionamiento del nuevo sistema no produzca un parón importante (lo que, inevitablemente, ocurrirá si no se adoptan medidas específicas para evitarlo); y también con la finalidad de que, tras un período razonable de rodaje, no se produzca un sensible empeoramiento de los tiempos medios de resolución de los asuntos logrados en los tres últimos años.

No trato, obviamente, de formular ningún plan de actuación: carezco del conocimiento y de la responsabilidad de gestión que me legitimen para ello. Hablo como un tercero ajeno a estas cuestiones, al que, como ciudadano, interesa el buen funcionamiento de un servicio público capital, y al que, como abogado en ejercicio, preocupan los intereses de sus clientes en obtener resoluciones solventes en plazos razonables. Fruto de estas preocupaciones son las reflexiones siguientes.

1) En los meses iniciales de rodaje del nuevo sistema será inevitable que una parte importante de los miembros de la Sala dedique sus esfuerzos a la tarea de formación de criterios sobre la concurrencia de interés casacional en los diversos tipos de asuntos, incluso formando parte de la Sección a que se refiere el artículo 90.2 (cuyo número de miembros no está limitado). Hablo de los Magistrados miembros de la Sala, ya que los actuales Letrados del Gabinete difícilmente podrán colaborar en la formación de unos criterios que tienen bastante más de políticos y estratégicos que de jurídicos. La actuación de estos Letrados será capital una vez se halle constituido un corpus considerable de cri- 
terios de admisión, con objeto de recordar a la Sección de admisiones las soluciones ya observadas en casos precedentes; pero no antes.

2) Preocupa seriamente el ritmo de adopción de los criterios de admisión en los meses iniciales de puesta en marcha del nuevo sistema (y también después). Un órgano colegiado de composición indeterminada y numerosa, integrado por personas de la calidad intelectual y acusada personalidad de los Magistrados del Tribunal Supremo es, sin duda, el foro menos adecuado para adoptar decisiones rápidas sobre cuestiones esencialmente opinables. Hubiera sido preferible que la toma de estas decisiones se encomendara a un órgano de composición muy restringida, o incluso a una sola persona, oyendo previamente a las que fuera conveniente; pero, a menos que ésta sea la práctica que se implante de facto en virtud de un pacto de caballeros, es de temer que las decisiones que se adopten en los primeros momentos se dilaten considerablemente.

3) El trámite de admisión debe ser utilizado conscientemente para lograr un volumen adecuado de asuntos a resolver en cuanto al fondo. La lamentable experiencia del Tribunal Constitucional aconseja evitar la probable imagen de decapitación masiva y proporcionalmente muy mayoritaria del número de recursos interpuestos; pero la admisión ha de servir, también, al objetivo de dar vía libre solo a un número de recursos adecuado a las posibilidades reales de resolución de la Sala.

Este número no ha de ser tan exiguo como el que se consigue en la práctica del Tribunal Constitucional. En el momento actual, el nivel de «productividad» que los miembros de la Sala Tercera se han visto forzados a autoimponerse ${ }^{12}$ para no generar más retrasos en el fallo de los asuntos es incompatible con un trabajo serio y meditado de resolución de conflictos, y explica, aunque no justifique plenamente, las discrepancias de criterio y el tono apodíctico de muchas sentencias, que tienen como causa principal la presión impuesta por el calendario de señalamientos. Redactar una buena sentencia, auténticamente crea-

12 Si se tiene en cuenta que el número de Magistrados de la Sala Tercera ha oscilado en este período en torno a la treintena, una sencilla operación aritmética pone de manifiesto que el número de asuntos resueltos por cada uno de ellos, a título de ponentes, hubo de ser, en 2005, año «de máxima producción» de resoluciones, de 439 (contando 220 días hábiles al año, 1,99 asuntos diarios, cifra que no requiere comentario alguno); y que, en el año de menor carga teórica de trabajo por número de nuevos asuntos ingresados (2014), el de recursos que cada Magistrado hubo de analizar y resolver ascendió a 185,5, algo menos de un asunto por día hábil de trabajo ( asuntos pendientes). 
dora de jurisprudencia y que, al tiempo, sea justa en la respuesta a las pretensiones de las partes, es una tarea de estudio y meditación que requiere no menos de una semana de trabajo, como sabemos bien los letrados que, desde la posición menos comprometida de parte (que nos permite no ser objetivos), redactamos los escritos correspondientes a asuntos relevantes. Multiplicando el número de semanas hábiles al año por el número de Magistrados que actualmente componen la Sala, resulta un número de sentencias muy estimable en comparación porcentual con el de recursos de previsible interposición.

4) No puedo dejar de formular una reflexión final acerca de la formación y talante de los miembros de la Sala que ha de resolver los futuros recursos de casación, y de sus colaboradores.

Hace tiempo que vengo escuchando a muchos de los primeros, así como a Magistrados de tribunales inferiores, el juicio de que no pocos de los miembros de la Sala Tercera no tienen su estructura mental adecuada al funcionamiento de un tribunal destinado primordialmente a forjar criterios jurisprudenciales abstractos; se dice de ellos, siempre con el mayor respeto, que son, más que nada, jueces, cuya preocupación principal es dar una solución justa y respetuosa con la ley a los conflictos que se les someten. No puedo afirmarlo con absoluta convicción, porque me limito a dar cuenta de lo que escucho; pero la lectura de muchas sentencias, y la seriedad de las personas que me hacen llegar esta reflexión me mueven a darle algún crédito. Obviamente, esta valoración nada tiene que ver con el nivel de conocimientos y la capacidad de raciocinio de los miembros de la Sala, que, por fortuna, sigue manteniendo los niveles de excelencia conseguidos hace muchos años.

Esta proclividad a la actuación más «judicial» que «jurisprudencial» de la Sala Tercera tiene mucho que ver con el ritmo de trabajo y de resolución de recursos, como pocas líneas más arriba señalé. De hecho, el recurso de casación ha terminado mutando su naturaleza original de sustitutivo del référé législatif en una segunda instancia de acceso restringido. Y, aunque la implantación del nuevo régimen no deberá hacer perder a los juzgadores su talante y preocupación judicial (porque los recursos de casación han de servir también a la satisfacción de pretensiones), parece evidente que se impone un cambio de mentalidad global, asumiendo francamente una función cuasilegislativa que hasta ahora se ha rechazado implícitamente; así lo demuestra la experiencia del recurso de casación en interés de la ley, como antes dije, cuyo elevadísimo porcentaje de demandas inadmitidas o rechazadas dice 
mucho de la resistencia a desempeñar el papel de formulador de auténticas normas jurídicas por vía interpretativa.

Y la puesta en marcha de la reforma ha de exigir, también, un replanteamiento en profundidad de la formación requerida y de las funciones que hayan de asignarse a los Letrados del Gabinete del Tribunal Supremo, muchos de los cuales, pese a sus calidades personales e intelectuales, han estado confinados al trabajo de desescombro, que dicen los juristas franceses; esto es, a la mera preparación de las decisiones de admisión o inadmisión de recursos por razones formales, igual que muchos de los colegas que sirven al Tribunal Constitucional. Por más necesaria que haya sido esta ingrata tarea, su dedicación exclusiva o primordial a la misma me parece un desperdicio de recursos humanos. No sé, ni me corresponde decirlo, qué trabajos más participativos en las decisiones han de asignárseles; me limito a esta leve llamada de atención, así como a recordar que el sistema de trabajo individual y exclusivo de cada Magistrado, que desde tiempos inmemoriales se practica entre nosotros, es una anomalía histórica llamada a extinguirse, por ineficiente, en estos tiempos de litigiosidad masiva.

Tras una relectura final del texto de la Ley de reforma (simplemente para prevenir olvidos de cuestiones capitales), el autor de estas páginas no puede dejar de sentir estremecimientos. La reforma es tan profunda que va a suponer un esfuerzo hercúleo para la Sala Tercera, y un reto del que solo cabe esperar y desear que salga lo más airosa posible. Si no podrá evitar las críticas que se producirán, al menos podrá contar con la comprensión de los comentaristas. Le deseamos suerte. 